Sham PC, Curtis D (1995) An extended transmission/disequilibrium test (TDT) for multiallele marker loci. Ann Hum Genet 59:323-336

Spielman RS, Ewens WJ (1996) The TDT and other familybased tests for linkage disequilibrium and association. Am J Hum Genet 59:983-989

Stuart A (1955) A test of homogeneity of the marginal distribution in a two-way classification. Biometrika 42:412-416

Wilson SR (1997) On extending the transmission/disequilibrium test (TDT). Ann Hum Genet 61:151-161

Address for correspondence and reprints: Dr. Pak Sham, Department of Psychological Medicine, Institute of Psychiatry, DeCrespigny Park, London SE5 8AF, United Kingdom. E-mail: p.sham@iop.bpmf.ac.uk

(C) 1997 by The American Society of Human Genetics. All rights reserved. 0002-9297/97/6103-0038\$02.00

Am. J. Hum. Genet. 61:778, 1997

\section{Reply to Sham}

To the Editor:

We thank Dr. Sham for his thoughtful comments on our paper and regret our incorrect statement that Sham and Curtis (1995) recommended separate analyses for fathers and mothers. We agree that heterozygous parents can be treated independently under the hypothesis of no linkage or no association and that, in general, they are not independent when there is linkage and association. We agree further with Dr. Sham that we did not study the consequences of stratification in our simulations. As we mentioned in our Discussion, we were thinking more of admixture as a source of association when linkage is absent.

We differ from Dr. Sham in standing by our statements concerning the distribution of $T_{m \text { het }}$. We had noticed, as he has, that the variance of the statistic may be greater than that for a $\chi^{2}$ variable, but our simulations focused on the whole distribution. The statements in our paper were therefore based on percentiles rather than just the variance. We made explicit mention of the significance level and power being well approximated by $\chi^{2}$ theory in our simulations at that time.

We have now performed simulations for populations from which samples had the degree of sparseness and imbalance shown in the example of Dr. Sham. We have found that power levels for Monte Carlo (MC) $-T_{\text {mhet }}$ were very similar to those obtained under the assumption of $\chi^{2}$. We also found the power of MC- $T_{m \text { met }}$ to be very similar to that of the Sham and Curtis likelihood ratio test, and it may even be greater under some circumstances.

There is theoretical interest in the statistic $T_{m}$ because power of the test can be predicted from a noncentral $\chi^{2}$ distribution for which the noncentrality parameter may be estimated. However, we stress that we did not advocate use of the $T_{m}$ statistic, even when it is used with a Monte-Carlo procedure.

$$
\text { NORMAN L. KAPLAN, }{ }^{1} \text { E. R. MARTIN, }{ }^{1,2} \text { AND }
$$$$
\text { B. S. WEIR }{ }^{2}
$$

${ }^{1}$ Biostatistics Branch, National Institute for

Environmental Health Science, National Institutes of Health, Research Triangle Park, North Carolina; and

${ }^{2}$ Program in Statistical Genetics, Department of

Statistics, North Carolina State University, Raleigh

\section{References}

Sham PC, Curtis D (1995) An extended transmission/disequilibrium test (TDT) for multiallele marker loci. Ann Hum Genet 59:323-336

Address for correspondence and reprints: Dr. Norman Kaplan, Biostatistics Branch, National Institute for Environmental Health Science, National Institutes of Health, P.O. Box 12233, Research Triangle Park, NC 27709. (1) 1997 by The American Society of Human Genetics. All rights reserved. 0002-9297/97/6103-0039\$02.00

Am. J. Hum. Genet. 61:778-779, 1997

\section{Family Cell Lines Available for Research-An Endangered Resource?}

To the Editor:

Diabetes continues to be a major health problem that is continuing to grow not only in the United States, but worldwide, at an escalating cost to the patient as well as to society. The cost to the individual is tremendous, and a shortened life span is the outcome regardless of whether expert care to delay late complications is available. The genetic factors that control the insulin-dependent type of diabetes, type 1 diabetes, are still not understood. Genomewide scanning has confirmed HLA as a major genetic factor for type 1 diabetes and a number of potential loci for contributing genes (Davies et al. 1994; Todd et al. 1996). This task was in part accomplished and progress accelerated by investigator-supported initiatives to establish large collections of DNA and cell lines from multiplex type 1 diabetes families. Some 5 years ago, emerging new human genome technologies were available, but there was a shortage of families with type 1 diabetes to be analyzed for genetic linkage or association between the disease and polymorphic markers on human chromosomes.

In a letter to the editor (Lernmark et al. 1990), the availability of cell lines and DNA from the Human Biological Data Interchange (HBDI), a not-for-profit orga- 
nization in Philadelphia, was announced. The initiative to HBDI was taken by the founder of the Juvenile Diabetes Foundation International, Lee Ducat, the mother of a child with type 1 diabetes and a long-term advocate for diabetes research. In cooperation with the Juvenile Diabetes Foundation International, a questionnaire was distributed to 10,000 families that were members of the Juvenile Diabetes Foundation. By selection of multiplex families from these questionnaires, it was possible for HBDI initially to offer a collection of $\sim 100$ type 1 diabetes multiplex families having an affected sib pair and two healthy parents. The family collection of HBDI has grown during the past 4 years with funding from the Juvenile Diabetes Foundation International. The most recent HBDI catalog of family pedigrees, cell lines, and DNA has 400 families with type 1 diabetes immortalized and available for distribution. A similar resource is available in the United Kingdom from the British Diabetic Association Warren Repository (Bain et al. 1990).

Are we fully utilizing the information acquired so far? An important task for HBDI is to make all genotypes available on the world wide web. Already individual groups are depositing raw genotype data (http:// www.well.ox.ac.ok/7Eplyons). Funding is sought for an HBDI database that would also prevent duplication of effort. HLA typing (provided by H.E.) is available on all the family members. There is also information about type 1 diabetes autoantibody markers (assays donated by G.E.). Since type 1 diabetes is a moving target, today other family members might have developed diabetes. Analysis of linkage or associations may need to be revised. An HBDI web site with all genotypes and disease data would be a tremendous public resource for both research and education. It is an important obligation for HBDI and the Juvenile Diabetes Foundation International, whose members donated the blood to establish this database.

The development of family repositories such as HBDI has enabled several milestones for diabetes research. The interest of investigators studying diabetes complications and from other diseases such as thyroid disease, autism, rheumatoid arthritis, and so on to establish similar collections have been underpinned by the efforts in type 1 diabetes. In 1990, Lernmark et al. believed that the availability of families from HBDI would be of great interest to the scientific community in promoting studies on the genetic susceptibility to type 1 diabetes. The survival of HBDI, however, is uncertain. Members of the genetics community may therefore want to utilize this resource while it is still available. Catalogs are available, and DNA and cell lines can be ordered, from the HBDI Repository (800-440-HBDI). Database searches and clinical information can also be obtained through the HBDI Information Center (800-345-4234).

ÅKe LERNMARK, ${ }^{1}$ GEORGE EISENBARTH, ${ }^{2}$ LEE DUCAT,
HENRY A. ERLICH, ${ }^{4}$ DENISE FAUSTMAN, ${ }^{5}$ NOEL K.
MACLAREN, ${ }^{6}$ JURG OTT, ${ }^{7}$ M. ALAN PERMUTT,
JIN-XIONG SHE, ${ }^{9}$ AND JOHN TODD ${ }^{10}$
Seattle; ${ }^{2}$ Barbara Davis Center for Childhood
Diabetes, Denver; ${ }^{3}$ Human Biological Data
Interchange, Philadelphia; ${ }^{4}$ Department of Human
Genetics, Roche Molecular Systems, Inc., Alameda;
${ }^{5}$ Immunobiology Laboratory, Massachusetts General
Hospital, Charlestown; ${ }^{6}$ Research Institute for
Children, Louisiana State University Medical School
and Children's Hospital, New Orleans; ${ }^{7}$ Laboratory of
Statistical Genetics, Rockefeller University, New York;
${ }^{8}$ Metabolism Division, Washington University School
of Medicine, St. Louis; ${ }^{9}$ Department of Pathology,
University of Florida, Gainesville; and ${ }^{10}$ Wellcome
Trust Centre for Human Genetics, University of
Oxford, Oxford

\section{References}

Bain SC, Bennett AH, Todd JA (1990) The British Diabetic Association Warren Repository. Autoimmunity 7:83-85

Davies JL, Kawaguchi Y, Bennett ST, Copeman JB, Cordell HJ, Pritchard LE, Reed PW, et al. (1994) A genome-wide search for human type 1 diabetes susceptibility genes. Nature 371:130-136

Lernmark A, Ducat L, Eisenbarth GE, Ott J, Permutt MA, Rubenstein P, Spielman R (1990) Family cell lines available for research. Am J Hum Genet 47:1028-1030

Todd JA, Farrall M (1996) Panning for gold: genome-wide scanning for linkage in type 1 diabetes. Hum Mol Genet 5: 1443-1448

Address for correspondence and reprints: Dr. Åke Lernmark, Department of Medicine, Box 357710, Robert H. Williams Laboratory, 1959 Pacific Avenue, Room K-165, Seattle, WA 98195-7710. E-mail: ake@u.washington.edu (C) 1997 by The American Society of Human Genetics. All rights reserved. 0002-9297/97/6103-0040\$02.00 